Audiology

Neurotology
Audiol Neurotol 2012;17:349-356

DOI: $\underline{10.1159 / 000341163}$
Received: February 7, 2012

Accepted after revision: June 18, 2012

Published online: August 15, 2012

\title{
Hypoxia-Inducible Factor and Vascular Endothelial Growth Factor Pathway for the Study of Hypoxia in a New Model of Otitis Media with Effusion
}

\author{
Qiuhong Huang $^{\mathrm{a}}$ Zhigang Zhang $^{\mathrm{a}}$ Yiqing Zheng $^{\mathrm{a}}$ Qingyin Zheng ${ }^{\mathrm{b}}$ \\ Suijun Chen ${ }^{a}$ Yaodong $\mathrm{Xu}^{\mathrm{a}}$ Yongkang Ou ${ }^{\mathrm{a}}$ Zeheng $\mathrm{Qiu}^{\mathrm{a}}$ \\ ${ }^{a}$ Department of Otolaryngology-HNS, Sun Yat-Sen Memorial Hospital, Sun Yat-Sen University, Guangzhou, \\ PR China; ${ }^{b}$ Department of Otolaryngology-HNS, Case Western Reserve University, Cleveland, Ohio, USA
}

\section{Key Words}

Animal model $\cdot$ Dysfunction - Eustachian tube $\cdot$

Hypoxia-inducible factor- $1 \alpha \cdot$ Vascular endothelial growth factor

\begin{abstract}
The hypoxia-inducible factor and vascular endothelial growth factor (HIF-VEGF) pathway in hypoxic conditions of the middle ear due to dysfunction of the eustachian tube is still unknown, but it is considered as one pathogenetic mechanism in otitis media. This study was designed to investigate the possible involvement of the HIF-VEFG pathway in otitis media with effusion induced by dysfunction of the eustachian tube. We adopted a soft palate approach to obstruct the orifice of the eustachian tube to establish otitis media in a rat model. Auditory evoked brainstem response and tympanometry were used as hearing function tests, hypoxia-related factors were examined by reverse transcriptase polymerase chain reaction (RT-PCR). The expression of hypoxia-related proteins was detected by Western blot and immunostaining. The model of otitis media with effusion was successfully induced by cauterizing the orifice of the eustachian tube. RT-PCR showed up-regulation of hypoxia-related factors in cauterized ears. Western blot and immuno-
\end{abstract}

staining showed that the expression of hypoxia-related proteins in cauterized ears was increased. Hypoxia-induced vascular proliferation and an increase in permeability may be one pathogenetic mechanism of otitis media due to dysfunction of the eustachian tube.

Copyright $\odot 2012$ S. Karger AG, Basel

\section{Introduction}

Otitis media with effusion (OME) is characterized by a nonpurulent effusion in the middle ear without symptoms of acute infection, which can occur during the resolution of acute otitis media once the acute inflammation has resolved. Symptoms usually involve hearing loss or aural fullness, but typically do not involve pain or fever [Otitis media with effusion in young children, 1994; American Academy of Family Physicians, 2004]. Generally, by the age of 10 , about $80 \%$ of children have had at least one episode of OME [Rosenfeld et al., 2004; Engel et al., 2005].

The causes of OME include genetic and environmental factors. Genetic susceptibility to OME interacts with environmental factors. The environmental factors include dysfunction of the eustachian tube (ET) [Hildmann and

\section{KARGER \\ Fax +4161306 1234 \\ E-Mail karger@karger.ch}

www.karger.com
(C) 2012 S. Karger AG, Basel

$1420-3030 / 12 / 0176-0349 \$ 38.00 / 0$

Accessible online at:

www.karger.com/aud
Dr. Yiqing Zheng

Department of Otolaryngology-HNS, Sun Yat-Sen Memorial Hospital

Sun Yat-Sen University, 107 Yanjiang West Road

Guangzhou 510120 (PR China)

Tel. +861390227 9262, E-Mail yiqingzheng@ hotmail.com 
Hildmann, 1993; Naim et al., 2003], as well as infection (bacterial biofilm) and allergy [Post, 2001].

Previous research on genetic contributions to OME utilized available HapMap data and an LD-base tagging approach, which suggested that the mucin 5 genomic region, encompassing $M U C 2$ and $M U C 5 A C / M U C 5 B$, is related to middle ear inflammation [Sale et al., 2011]. Moreover, hypoxia-inducible factor (HIF) in hypoxic conditions due to ET dysfunction plays an important role in the mechanism of OME. The ET is the only route through which the middle ear can exchange gas with the atmosphere. Dysfunction of ET and the gas exchange mechanism in the middle ear are important factors that affect the induction and persistence of OME [Aoki et al., 1998]. Takahashi et al. [2009] reported that ET dysfunction induces hypoxic conditions in the middle ear of patients with OME. Additionally, in hypoxic conditions, hypoxia induces the expression of a group of physiologically important genes such as VEGF (vascular endothelial growth factor) [Cheeseman et al., 2011; Zhou et al., 2012]. Middle ear hypoxia resulting from ET obstruction and causing the release of hypoxia-induced factors and cytokines has recently been proposed as another mechanism of OME [Johnson et al., 1997; Portier et al., 1999; Pospiech et al., 2000; Smirnova et al., 2002].

However, although the hypothesis of hypoxia as a mechanism of OME was formulated several years ago, in the middle ear with effusion caused by ET dysfunction, the expression of HIF-1 and VEGF and their roles in the mechanism of OME are still unknown. In our study, we induced OME in rats via trichloroacetic acid cauterization of the pharyngeal orifice of the ET. This model was developed to study the hypoxia mechanism of otitis media due to dysfunction of the ET.

\section{Methods}

Animals

This study protocol was approved by the Animal Care and Use Committee of Sun Yat-sen University. Twenty Sprague-Dawley rats (12 males and 8 females, average weight $300 \mathrm{~g}$ ), free from middle ear disease as evaluated by otoscopic examination and by acoustic immittance, were used as experimental subjects (right ear). Another 20 animals (20 right ears) were used as untreated controls.

\section{Cauterization Protocol}

The OME model was created by cauterization of the pharyngeal orifice of ET. We adopted a soft palate approach as follows. An incision was made to open the soft palate, and the pharyngeal orifice of the rat's ET was identified under an otoendoscope
(Storz). We used a cotton swab dipped in 50\% trichloroacetic acid (Shanghai Shunqiang Biotechnology Co. Ltd.) to cauterize the orifice of the ET and to establish the otitis media animal model. Antibiotics (sulfamethoxazole, Beijing Yanjing Pharmaceutical Factory) were administered orally after the operation to prevent infection.

\section{ABR Thresholds and Tympanometry Analysis}

A computer-aided evoked potential system (Intelligent Hearing Systems) was used to test the rat's auditory evoked brainstem response $(\mathrm{ABR})$ thresholds as previously described [Zheng et al., 1999]. Broadband clicks ( $8-16 \mathrm{kHz})$ and $8-, 16-$, and $32-\mathrm{kHz}$ puretone bursts were, respectively, presented to the rats. Animals were placed in a supine position and a skin needle electrode was used to record the response threshold. The recording electrode was placed on the cranial-parietal line of the rat. The reference electrode was placed in the postauricular position, and the zero electrode was placed on the nasal root. Rats were exposed to a short sound stimulus.

Biological signals were bandpass-filtered below $100 \mathrm{~Hz}$ and above $3000 \mathrm{~Hz}$ and amplified 200000 times; an A/D sampling rate of $25 \mathrm{kHz}$ was employed. Artifact rejection level was set at 31.00 $\mu \mathrm{V}$. The amplified responses were averaged by a computer and displayed on the computer screen. Analysis time was $10 \mathrm{~ms}$. Auditory thresholds were obtained for each stimulus by reducing the SPL at $10-\mathrm{dB}$ steps and finally at 5-dB steps up and down to identify the lowest level at which an ABR could be recognized. The ABRs were typically identified with 128-512 stimuli presented at a rate of 19.1/s; low-amplitude responses required more stimulus presentations to verify an ABR pattern just above its threshold.

Tympanometry, an examination used to test the condition of the middle ear and the mobility of the tympanic membrane and ossicular chain by creating variations of air pressure in the ear canal, was performed following the procedures described before [Zheng et al., 2007] by using an MT10 tympanometer from Interacoustics (Assens, Denmark). Prior to ABR or tympanometric measurement, rats were anesthetized with Avertin $(0.5 \mathrm{mg} / \mathrm{g}$ rat mass) by intraperitoneal injection. Both assays were performed prior to cauterization and at 6 days following the challenge.

\section{Histological Analysis of Middle and Inner Ears}

After cauterization 4 rats chosen randomly each from cauterized and untreated control groups were sacrificed, and the bullae (including both the middle and inner ear) were isolated. Histological analyses were performed following the methods described previously [Johnson et al., 2003]. Briefly, the middle and inner ears from cauterized and untreated control rats were dissected, perfused with $1.5 \%$ paraformaldehyde fixative, immersed in the same fixative for $48 \mathrm{~h}$, decalcified with $10 \%$ EDTA solution for 7 days, and embedded in paraffin. Sections $(6 \mu \mathrm{m})$ were cut, mounted on glass slides, and counterstained with hematoxylin/eosin.

Semiquantitative RT-PCR for Determining $m R N A$

Accumulation of Hypoxia-Related Genes

Total RNA (DNA-free) was prepared from the right bullae of 4 rats from both groups using the PureLink ${ }^{\mathrm{TM}}$ Micro-to-Midi Total RNA Purification System (Invitrogen). First-strand cDNA was synthesized using a SuperScript First-Strand Synthesis System with $2 \mu \mathrm{g}$ of total RNA template from each sample. Reverse transcriptase polymerase chain reaction (RT-PCR) was carried out to 
Table 1. Sequences of primers used in RT-PCR

\begin{tabular}{|c|c|c|}
\hline Primer & Oligonucleotide sequence $\left(5^{\prime}-3^{\prime}\right)$ & Size, bp \\
\hline $\mathrm{HIF}-1 \alpha \mathrm{F}$ & GAA CAA AAC ACA CAG CGA AGC T & \multirow{2}{*}{143} \\
\hline $\mathrm{HIF}-1 \alpha \mathrm{R}$ & TGG TTA CTG TTG GTA TCA TAT ACG TGA A & \\
\hline IL-1 $\beta$ F & TCATGGGATGATGATGATAACCTGCT & \multirow{2}{*}{502} \\
\hline IL-1 $\beta$ R & CCCATACTTTAGGAAGACACGGATT & \\
\hline VEGF F & GAG GGC AGA ATC ATC ACG AAG T & \multirow{2}{*}{127} \\
\hline VEGF R & GGC TTG AAG ATG TAC TCG ATC TCA T & \\
\hline GapdhF & AACTTTGGCATTGTGGAAGG & \multirow{2}{*}{351} \\
\hline GapdhR & GGAGACAACCTGGTCCTCAG & \\
\hline TNF- $\alpha \mathrm{R}$ & CCTTGAAGAGAACCTGGGAGT & \multirow{2}{*}{303} \\
\hline $\mathrm{TNF}-\alpha \mathrm{F}$ & CCACCACGCTCTTCTGTCTAC & \\
\hline
\end{tabular}

reveal the profiles of mRNA accumulation of HIF- $1 \alpha$, VEGF, IL$1 \beta$, and TNF- $\alpha$. The primers used for these genes are listed in table 1 . The $20-\mu l$ reaction mixture contained $50 \mathrm{mM} \mathrm{KCl}, 10 \mathrm{mM}$ Tris- $\mathrm{HCl}\left(\mathrm{pH} 9.0,25^{\circ} \mathrm{C}\right), 0.01 \%$ Triton X-100, $2 \mathrm{mM} \mathrm{MgCl}_{2}, 250$ $\mathrm{nM}$ of each primer (forward and reverse), $200 \mu \mathrm{M}$ deoxynucleoside triphosphate, $1 \mu \mathrm{l}$ of cDNA, and $0.5 \mathrm{U}$ of Taq DNA polymerase (New England BioLabs). PCR was performed in a Bio-Rad PTC-200 Peltier thermal cycler. The amplification consisted of an initial denaturation at $94^{\circ} \mathrm{C}$ for 2 min followed by 28 cycles at $94^{\circ} \mathrm{C}$ for $30 \mathrm{~s}, 60^{\circ} \mathrm{C}$ for $40 \mathrm{~s}$, and $72^{\circ} \mathrm{C}$ for $50 \mathrm{~s}$ and then a final extension of $72^{\circ} \mathrm{C}$ for $2 \mathrm{~min}$. A total of $10 \mu \mathrm{l}$ of each PCR product was subjected to agarose gel electrophoresis. The gray intensity of each band on the agarose gel was digitized using ImageJ software (NIH) and corrected by the coefficient of the GAPDH (glyceraldehyde-3-phosphate dehydrogenase) gene expression level of the same sample.

\section{Immunostaining for HIF-1 $\alpha$ and VEGF}

Paraffin sections of the middle and inner ear prepared as described above [Johnson et al., 2003] were then covered with $0.05 \%$ trypsin solution (containing $0.1 \%$ calcium chloride, $\mathrm{pH} 7.8$ ) and incubated in a humidified chamber at $37^{\circ} \mathrm{C}$ for $20 \mathrm{~min}$. After being washed twice in $1 \times$ phosphate-buffered saline ( 5 min each) and blocked in $5 \%$ bovine serum albumin for $1 \mathrm{~h}$, the samples were immersed in rabbit anti-rat polyclonal antibodies (1:200 dilution) and incubated at $4{ }^{\circ} \mathrm{C}$ overnight. The HIF- $1 \alpha$ antibody $(1000 \mathrm{mg} / \mathrm{ml})$ and VEGF antibody $(0.500 \mathrm{mg} / \mathrm{ml})$ were purchased from Abcam Inc. (Cambridge, Mass., USA). Then the samples were washed twice in $1 \times$ phosphate-buffered saline for $5 \mathrm{~min}$ each, respectively, immersed in goat anti-rabbit secondary antibody conjugated to Alexa Fluor 488 (1:500 dilution; Invitrogen), and HRP anti-rabbit secondary antibody incubated at room temperature for $1 \mathrm{~h}$. The mounted samples were observed under an immunofluorescence microscope (Leica).

\section{Western Blot Analysis}

Protein levels of HIF-1 $\alpha$ were also analyzed using Western blot. Tissues dissected from treated and untreated rats were homogenized with a rotor/stator tissue homogenizer in RIPA buffer supplemented with $1 \mathrm{mM}$ PMSF and a mix of additional protease inhibitors (Halt Proteinase Inhibitor Cocktail; Thermo Scientific,
Rockford, Ill., USA). Total tissue lysates were centrifuged at 14000 rpm for $20 \mathrm{~min}$ at $4^{\circ} \mathrm{C}$. Protein concentration in the resulting supernatant was determined using the BCA protein assay reagent (Sigma-Aldrich, St. Louis, Mo., USA). Using $50 \mu \mathrm{g}$ of lysate per lane, protein from each tissue was electrophoresed on $7.5 \%$ SDSPAGE gels and transferred to PVDF membrane (Bio-Rad). Membranes were blocked for $1 \mathrm{~h}$ at room temperature in $5 \%$ non-fat milk in TBST. Primary antibody was incubated with membranes at $4{ }^{\circ} \mathrm{C}$ overnight using a $1: 2000$ dilution of anti-HIF-1 $\alpha$ rabbit polyclonal antibody. After washing with TBST, membranes were incubated for $1 \mathrm{~h}$ at room temperature with secondary antibody diluted 1:2000 (IRDye680 goat anti-rabbit IgG, LI-COR Biosciences).

\section{Statistics}

Data were analyzed using the Student $t$ test; a p value of $<0.05$ was considered significant.

\section{Results}

\section{Confirmation of $O M E$}

The survival rate in the cauterization-treated group was 15/20 (88.2\%), in which $2(5.9 \%)$ rats died due to anesthesia, and $1(2.9 \%)$ rat died 4 days after the operation perhaps because of trauma and difficulty in feeding, 2 (5.9\%) rats had no change in the middle ear. Middle ear fluid was observed in 15 of the cauterized ears.

Compared with the transparent tympanic membranes of the untreated control ears, middle ear effusion in the cauterized ears was also observed 6 days after cauterization (fig. 1a, b). Differences in the static volume of middle ear compliance and the middle ear peak pressure were observed between the cauterized and untreated control ears 6 days after cauterization. Both compliance and pressure of tympanometry decreased in all cauterized ears 6 days after cauterization; there was a significant dif- 
Fig. 1. a Untreated control ear. The normal tympanic membrane (TM) of the rat is translucent and consists of the pars tensa and pars flaccida. The white malleus (M) is clearly visible $\left(^{*}\right)$. The area of the TM is about $2 \times 3 \mathrm{~mm}$. b Cauterized ear. The status of the TM 6 days after the operation. Intact TM with effusion exudate in the otocyst.

Fig. 2. Results of tympanometry. a Compliance values in untreated control and cauterized ears before and 6 days after cauterization $(\mathrm{n}=15)$. $\mathbf{b}$ Pressure in untreated control ears and cauterized ears before and 6 days after cauterization $(n=15)$. The mean values of compliance and pressure show significant decreases from the baseline readings 6 days after cauterization (asterisks). Each error bar represents the standard deviation calculated for each mean. ${ }^{* *} \mathrm{p}<0.01$.

Fig. 3. Comparison of mean ABR thresholds at stimulus frequencies of click, 8, 16 and $32 \mathrm{kHz}$ between the untreated control ears and cauterized ears 6 days after cauterization. The mean ABR threshold of cauterized ears was significantly higher than that in untreated control ears at stimulus frequencies of click, 8,16 and $32 \mathrm{kHz}$ $(\mathrm{n}=15, \mathrm{p}<0.05)$.
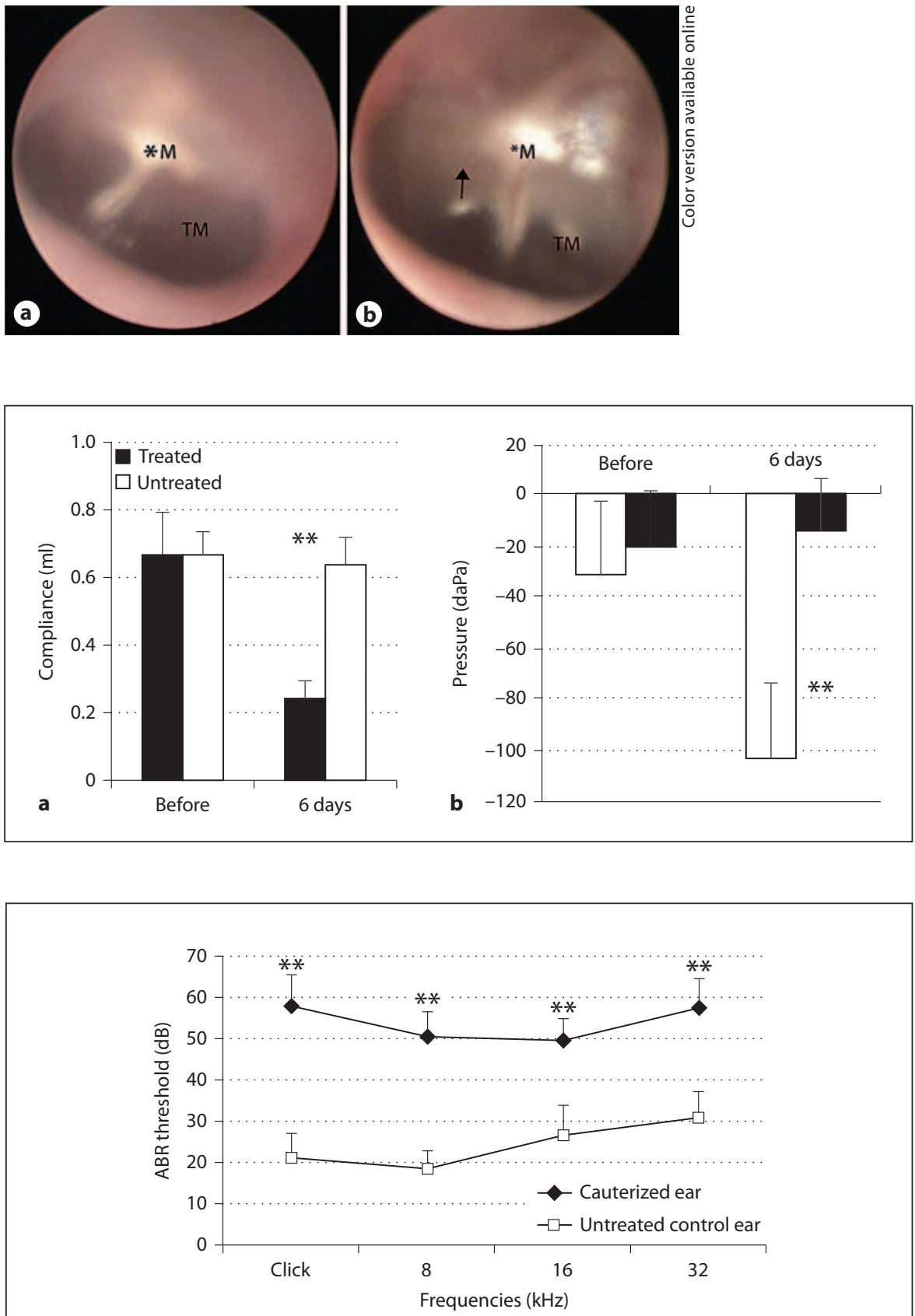

ference between the two groups $(\mathrm{n}=15, \mathrm{p}=0.0012$, 0.0034, respectively; fig. 2a, b). Additionally, ABR thresholds increased in cauterized ears for clicks, 8, 16 and 32 $\mathrm{kHz}$ frequencies after 6 days of cauterization, and cauterized ears showed a significant difference in ABR thresholds compared to untreated control ears $(\mathrm{n}=15, \mathrm{p}=0.024$, $0.042,0.039,0.048$, respectively; fig. 3 ).

Middle Ear Histology

Histological examination of cauterized ears showed a lot of effusion infiltrating the middle ear; there were large numbers of inflammatory cells infiltrating into the lamina propria (fig. 4a). Figure 4b, c show edema and inflammatory cells obstructing the ET in cauterized ears. Epithelial thickening can also be seen in cauterized middle 

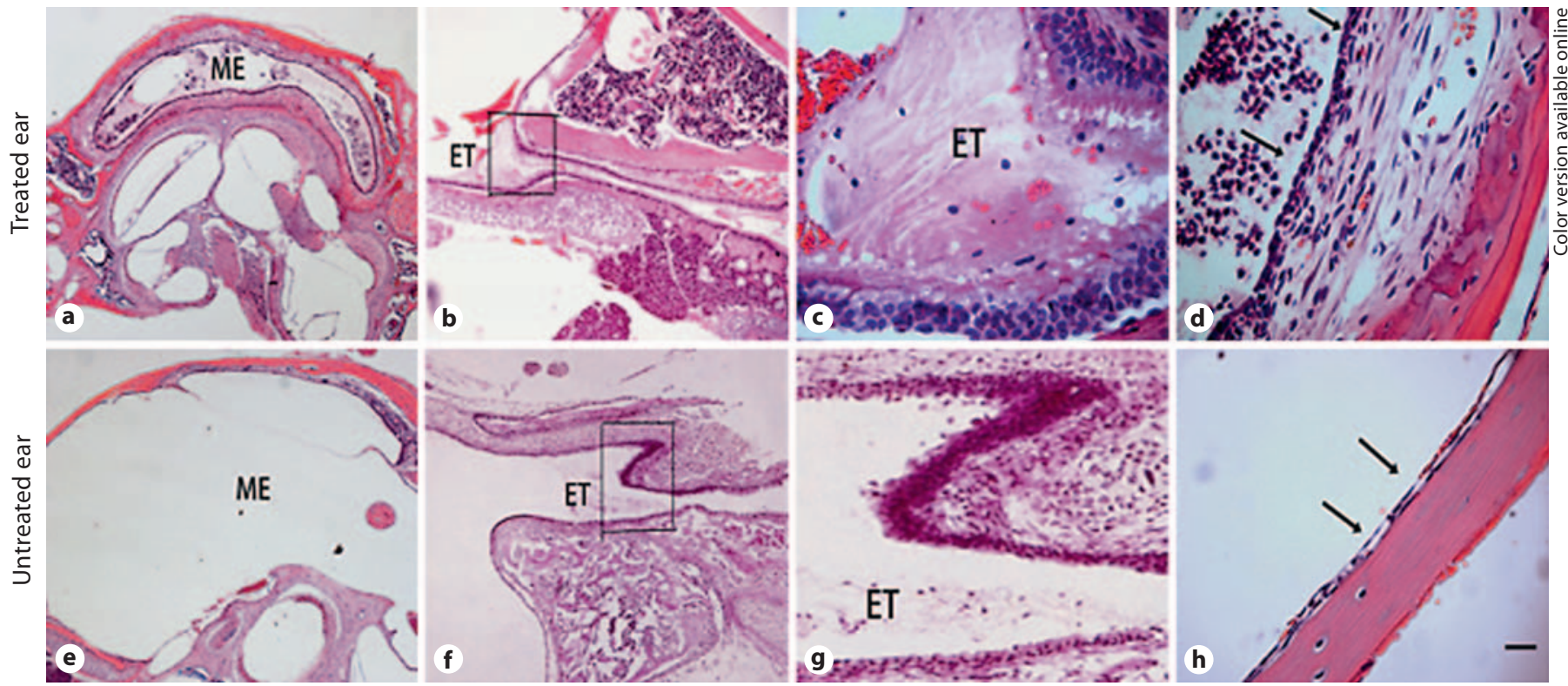

Fig. 4. a-d Histological section of inner and middle ear (ME) after cauterization showing effusion and inflammatory cells infiltrating into the middle ear cavity (a), effusion and inflammatory cells, even mucosal edema obstructing the orifice of the ET (b, c), and thickened surrounding epithelium (d). e-h Histological section of inner and middle ear from untreated control ears showing normal anatomy and absence of cellular infiltrate in the middle ear (e). Clear and unobstructed orifice of ET $(\mathbf{f}, \mathbf{g})$. Single epithelium is thin (h). All inner ear structures are normal in appearance. The different size of the middle ear cavity between $\mathbf{a}$ and $\mathbf{e}$ is an artifactual consequence of a slightly different plane of section. Scale bar, $15 \mu \mathrm{m}$.

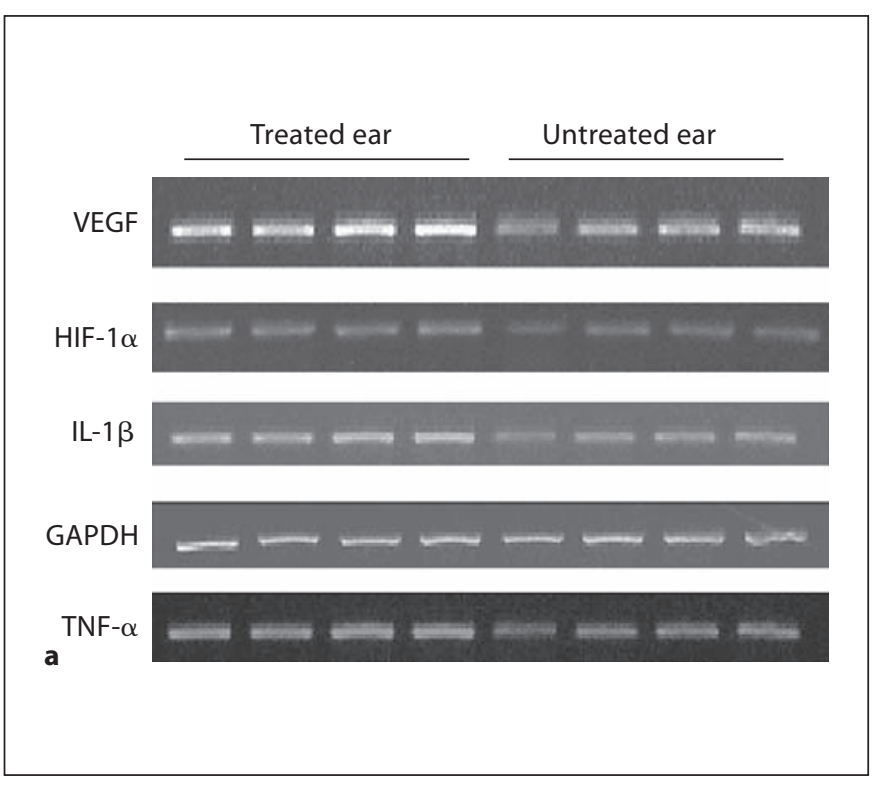

Fig. 5. a mRNA accumulation levels for hypoxia-related and proinflammatory genes from middle ears of untreated controls and cauterized ears. After $2 \%$ agarose gel electrophoresis of RT-PCR products, the bands were digitized for GAPDH, VEGF, HIF- $1 \alpha$, IL-1 $\beta$, TNF- $\alpha$. b The GAPDH-corrected mRNA accumulation

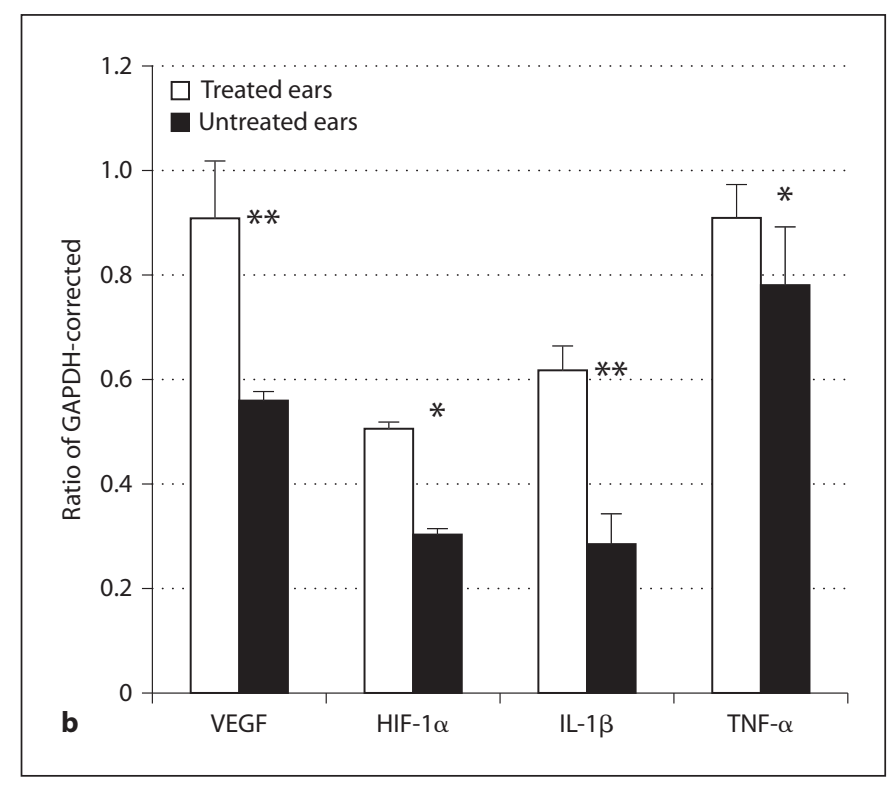

levels were averaged for each group, with error bars indicating standard deviations from the means. Quantification of the mRNA accumulation levels of all the genes were significantly higher in cauterized ears than in untreated control ears $\left(\mathrm{n}=4,{ }^{*} \mathrm{p}<0.05\right.$; ** $\mathrm{p}<0.01)$. 
Fig. 6. Immunostaining with horseradish peroxidase secondary antibody for HIF- $1 \alpha$ from middle ear mucosa of untreated control ears and cauterized ears. Greater level of HIF- $1 \alpha$ in cauterized ears than in untreated control ears; HIF- $1 \alpha$ is mainly expressed in the nucleus, as well as in the cytoplasm (a, b). Western blot showed a higher level of HIF-1 $\alpha$ in cauterized ears than in untreated control ears, while $\beta$-actin is at the same level (c). Scale bar, $15 \mu \mathrm{m}$.

Fig. 7. Immunofluorescence staining for VEGF from middle ear mucosa of untreated control (a) and cauterized ears (b). Expression of VEGF in cauterized ears was higher than in untreated control ears. $\mathrm{ME}=$ Middle ear. Scale bar, $15 \mu \mathrm{m}$.
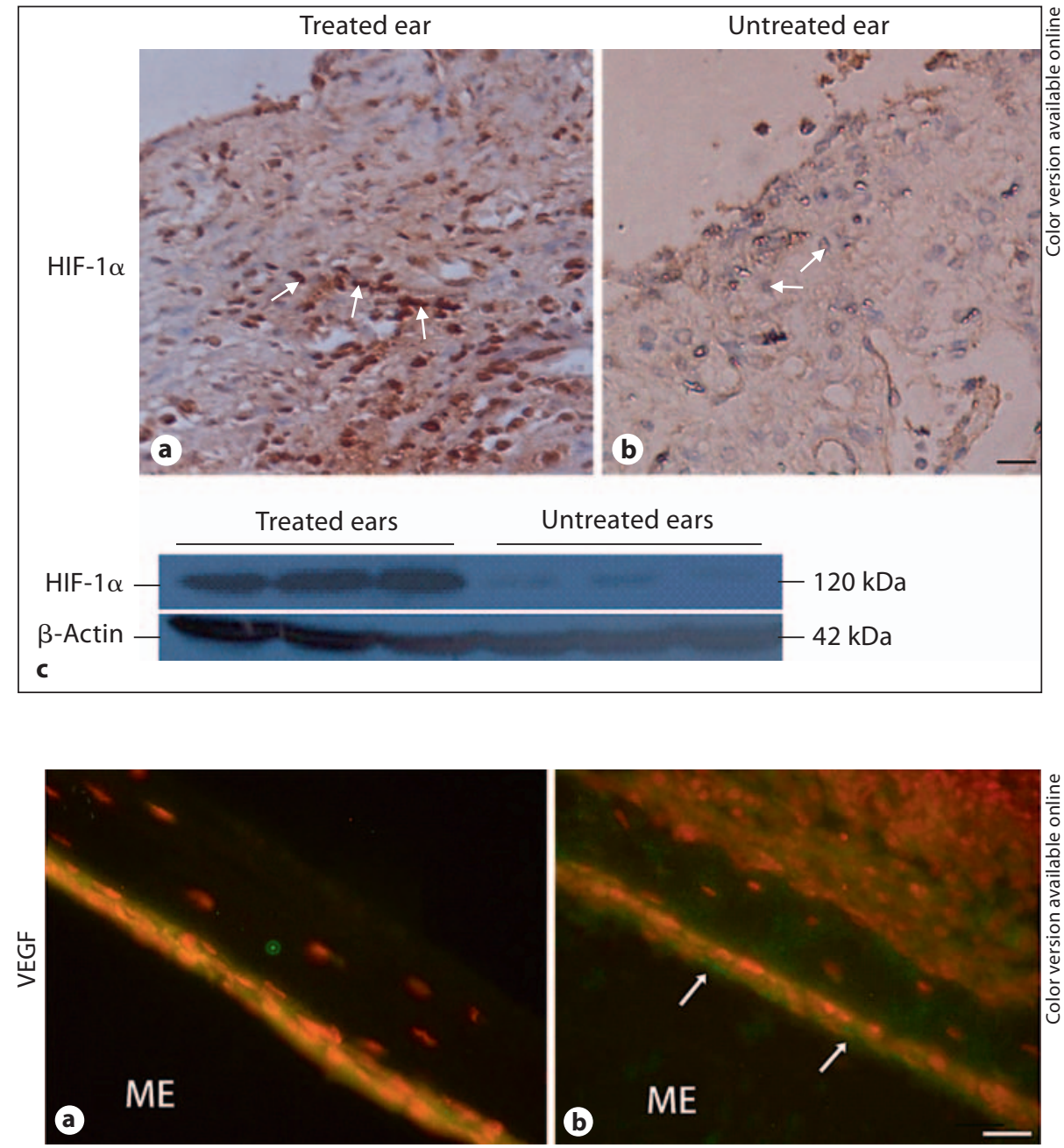

ears compared to untreated control ears (fig. 4d, h). Figure $4 \mathrm{e}-\mathrm{g}$ show normal middle ears in untreated control ears.

\section{Hypoxia-Related Gene Expression in Cauterized Ears}

After formation of OME, 4 rats were chosen randomly from each group to be assessed for mRNA accumulation levels of hypoxia-related genes. GAPDH-corrected RT-PCR results showed that the mRNA accumulations of HIF- $1 \alpha$, VEGF and IL-1 $\beta$, and TNF- $\alpha$ in cauterized ears were significantly higher than mRNA levels in untreated controls $(\mathrm{n}=4, \mathrm{p}=0.0024,0.031,0.0084,0.042$, respectively; fig. 5a, b).

\section{Immunostaining for HIF-1 $\alpha$ and VEGF: Increase in}

Hypoxia-Related Protein Levels in Cauterized Ears

To confirm that the increase in mRNA accumulation of hypoxia-related genes was correlated with protein ex- pression levels, we stained with fluorescein isothiocyanate-anti-VEGF 7 days after cauterization and with enzyme HRP-anti-HIF-1 $\alpha$. The expression of HIF-1 $\alpha$ (fig. 6a, b) and VEGF (fig. 7a, b) in cauterized ears was greater than that in untreated control ears.

Western Blot for HIF-1 $\alpha$ Reveals an Increased Level in Cauterized Ears

We also used Western blot to detect HIF- $1 \alpha$ to confirm the increased expression of HIF- $1 \alpha$ in cauterized ears. $\beta$ Actin showed the same levels in the two groups. A band of $120 \mathrm{kDa}$ was detected in protein lysates isolated both from tissues of 4 cauterized and untreated control ears (fig. 6c). 


\section{Discussion}

In this study, we established a new rat model of OME to investigate the role of hypoxia in otitis media. In our study, Sprague-Dawley rats were chosen as the model because the temporal bone structure in rats is similar to that in humans [Salomonsen et al., 2010]. Sprague-Dawley rats have been widely used as an animal model in otology research, including models of otitis media and other middle ear diseases [Sade et al., 1959; Vicente et al., 2007].

Previous studies reported the establishment of OME in rats through bipolar electrocoagulation of the ET pharyngeal orifice [Kuijpers et al., 1979] or through endotoxin induction [Krekorian et al., 1990]. Based on findings of previous studies [Sade et al., 1959; Kuijpers et al., 1983; Song et al., 2009], we created a modified method of thermochemically cauterizing the ET (trichloroacetic acid cauterization) to establish an OME model with a high success rate. Compared to previous methods, trichloroacetic acid is universally used in hospital or research settings. Compared to bipolar electrocoagulation, it is cheap and available in labs. In contrast to studies using endotoxin or Streptococcus pneumoniae, our study was targeted at ET dysfunction rather than middle ear infection.

In our study, histological findings provide direct evidence to verify our OME rat model. However, tympanometry and $\mathrm{ABR}$ were also used to confirm the formation of OME in the rat model. The compliance and pressure of tympanometry decreased in all cauterized ears 6 days after cauterization. This finding appeared to be correlated with the obstruction of ET and the fact that the middle ear cannot exchange gas with the atmosphere. Upon comparison of the ABR response threshold between untreated controls and cauterized ears, there was significant change, which may be due to the presence of effusion; it is expected that the tympanic membrane and the cochlear window would be affected, altering the structure and function of sound transmission, and ultimately causing an increase in the stiffness and responsiveness of the ossicular chain, and thus increasing the response threshold.

HIF- $1 \alpha$, a member of the HIF family, is a transcription factor that responds to changes in available oxygen in the cellular environment, specifically, to decreases in oxygen or hypoxia [Smith et al., 2008]. The HIF signaling cascade mediates the effects of hypoxia, a state of low oxygen concentration, on the cell. HIF-1 will then up-regulate hypoxia-related genes in hypoxic conditions, such as VEGF. HIF- $1 \alpha$ does not only induce an increase in VEGF, but it can induce excess expression of VEGF mRNA and extend the half-life of mRNA VEGF at the same time. VEGF is a hypoxia-inducing angiopoietic growth factor with positive regulation function, with a potent and critical inducer of angiogenesis and vascular permeability, and has been shown to play an important role in inflammatory events, together with hypoxia and inflammatory cytokines (TNF- $\alpha$, IL-1 $\beta$ ), that are considered to be the most potent vascular permeability-enhancing factors inducing otitis media [Ladoux and Frelin, 1993; Naim et al., 2004; Obrosova et al., 2004]. In our study, the mRNA accumulation of HIF- $1 \alpha$, VEGF, TNF- $\alpha$ and IL- $1 \beta$ in cauterized ears was significantly higher than the mRNA levels in untreated controls. This result can be explained by middle ear hypoxia due to ET obstruction after cauterization. Immunostaining of HIF- $1 \alpha$ and VEGF, as well as Western blot showed a higher expression of protein levels in cauterized ears, taken together, which indicates that hypoxia may be the core factor to induce the transcription of HIF- $1 \alpha$, VEGF, TNF- $\alpha$ and IL- $1 \beta$ genes, and the translation of HIF-1 $\alpha$, VEGF proteins, which cause vascular proliferation and increased permeability in otitis media.

This study showed a new way of establishing a rat model of OME. Hypoxia-induced vascular proliferation and increased permeability may be pathogenetic factors in OME due to ET dysfunction.

\section{Acknowledgment}

We wish to thank Dr. Cindy Benedict-Alderfer for editing this article. This work was funded by National Natural Science Foundation of China (No. 81170921).

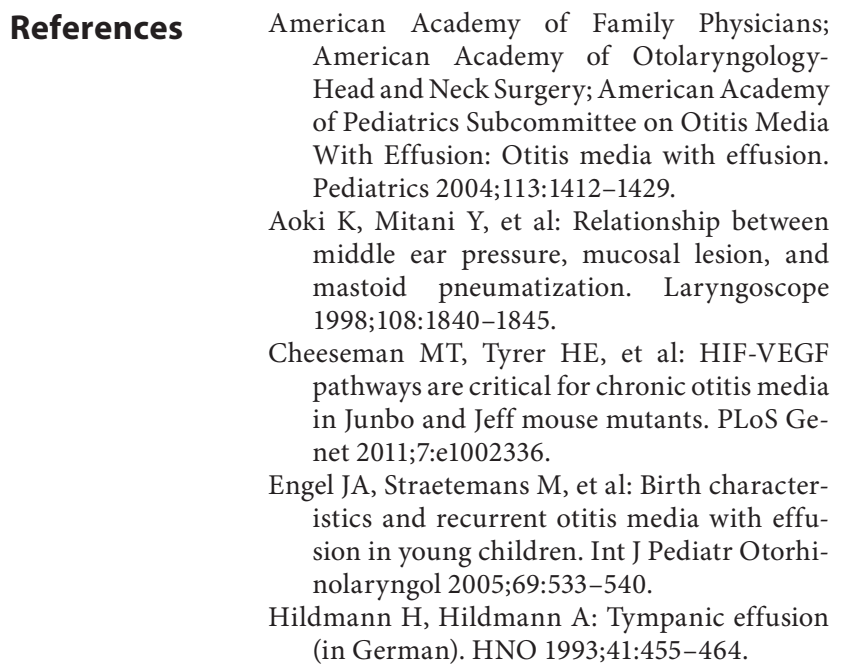

Audiol Neurotol 2012;17:349-356 355 
Johnson KR, Gagnon LH, et al: Mouse models of USH1C and DFNB18: phenotypic and molecular analyses of two new spontaneous mutations of the Ush1c gene. Hum Mol Genet 2003; 12:3075-3086.

Johnson M, Leonard G, et al: Murine model of interleukin-8-induced otitis media. Laryngoscope 1997;107:1405-1408.

Krekorian TD, Keithley EM, et al: Endotoxininduced otitis media with effusion in the mouse. Immunohistochemical analysis. Acta Otolaryngol 1990;109:288-299.

- Kuijpers W, van der Beek JM, et al: 'The effect of experimental tubal obstruction on the middle ear. Preliminary report'. Acta Otolaryngol 1979;87:345-352.

Kuijpers W, van der Beek JM, et al: Experimental model for the study of otitis media with effusion. Acta Otorhinolaryngol Belg 1983;37: 135-137.

Ladoux A, Frelin C: Hypoxia is a strong inducer of vascular endothelial growth factor mRNA expression in the heart. Biochem Biophys Res Commun 1993;195:1005-1010.

- Naim R, Riedel F, et al: Expression of vascular endothelial growth factor in external auditory canal cholesteatoma. Int $\mathrm{J}$ Mol Med 2003; 11:555-558.

-Naim R, Sadick H, et al: External auditory canal cholesteatoma: analysis of the integrity of the tissue structure. Int J Mol Med 2004;14:601604.
Obrosova IG, Minchenko AG, et al: Poly(ADPribose) polymerase inhibitors counteract diabetes- and hypoxia-induced retinal vascular endothelial growth factor overexpression. Int J Mol Med 2004;14:55-64.

Otitis media with effusion in young children. Guideline overview. Agency for Health Care Policy and Research, Rockville, Maryland. J Natl Med Assoc 1994;86:731-732, 792-733.

Portier F, van den Abbeele T, et al: Oxygen modulates $\mathrm{Na}+$ absorption in middle ear epithelium. Am J Physiol 1999;276:C312-C317.

Pospiech L, Jaworska M, et al: Soluble L-selectin and interleukin-8 in otitis media with effusion. Auris Nasus Larynx 2000;27:213-217.

Post JC: Direct evidence of bacterial biofilms in otitis media. Laryngoscope 2001;111:20832094.

Rosenfeld RM, Culpepper L, et al: Otitis media with effusion clinical practice guideline. Am Fam Physician 2004;69:2776, 2778-2779.

Sade J, Carr CD, et al: Middle ear effusions produced experimentally in dogs. I. Microscopic and bacteriologic findings. Ann Otol Rhinol Laryngol 1959;68:1017-1027.

Sale MM, Chen WM, et al: Evaluation of 15 functional candidate genes for association with chronic otitis media with effusion and/or recurrent otitis media (COME/ROM). PLoS One 2011;6:e22297.

Salomonsen RL, Hermansson A, et al: Ossicular bone modeling in acute otitis media. Otol Neurotol 2010;31:1109-1114.
Smirnova MG, Kiselev SL, et al: Role of the proinflammatory cytokines tumor necrosis factor-alpha, interleukin-1 beta, interleukin- 6 and interleukin- 8 in the pathogenesis of the otitis media with effusion. Eur Cytokine Netw 2002;13:161-172.

Smith TG, Robbins PA, et al: The human side of hypoxia-inducible factor. $\mathrm{Br} \mathrm{J}$ Haematol 2008;141:325-334.

Song JJ, Kown SK, et al: Mucosal expression of $\mathrm{ENaC}$ and $\mathrm{AQP}$ in experimental otitis media induced by Eustachian tube obstruction. Int J Pediatr Otorhinolaryngol 2009;73:15891593.

Takahashi E, Kikuchi T, et al: Localization of aquaporins, water channel proteins, in the mouse eustachian tube. Acta Otolaryngol Suppl 2009;562:67-70.

-Vicente J, Trinidad A, et al: Evolution of middle ear changes after permanent eustachian tube blockage. Arch Otolaryngol Head Neck Surg 2007;133:587-592.

Zheng QY, Johnson KR, et al: Assessment of hearing in 80 inbred strains of mice by ABR threshold analyses. Hear Res 1999;130:94107.

Zheng QY, Tong YC, et al: Tympanometry assessment of 61 inbred strains of mice. Hear Res 2007;231:23-31.

Zhou H, Chen ZB, et al: Effects of hypoxia-inducible factor $1 \alpha$ on bone conduction impairment in otitis media with effusion. Acta Otolaryngol 2012, E-pub ahead of print. 